\title{
Wireless Indoor Positioning Algorithm Based on PCA
}

\author{
H.L. Li \\ Communication Engineering \\ Jilin University \\ Jilin, China \\ W. Quan \\ Communication Engineering \\ Jilin University \\ Jilin, China
}

\author{
Z.H. Qian \\ Communication Engineering \\ Jilin University \\ Jilin, China \\ G. Ji \\ State Grid Changchun Power Supply Company \\ Changchun, Jilin, China
}

\begin{abstract}
The use of WLAN (Wireless Local Area Networks)for indoor localization is an important content in the field of mobile Internet, usually based on the Received Signal Strength(RSS) and the fingerprinting algorithms. Due to the characteristics of the RSS, environmental factors have great influence on the RSS value. So this paper proposes to extract RSS feature samples using the PCA (Principal Component Analysis)and use the KNN(k-Nearest Neighbour algorithm) to locate. The simulation show that the algorithm has the stronger ability of anti-jamming and better positioning accuracy than the $\mathrm{KNN}(\mathrm{k}$-Nearest Neighbour algorithm) algorithm.
\end{abstract}

\section{Keywords-WLAN; PCA; KNN; Localization}

\section{INTRODUCTION}

After the emergence of the concept of the Internet of things[1],more increasing user demands on LBS(Location-based Services) and SNS(Social Networking Services), indoor positioning has become more crucial. Because of the general failure of GPS(Global Positioning System) indoors, non-satellite-based technologies, therefore, are important for indoor localization[2].WLAN (Wireless Local Area Networks) have widely been employed for indoor location fingerprinting technique which is one of the suggested methods for indoor positioning [3-5]. This technique requires a survey of RF(Radio Frequency) signal strength vectors to be made ahead of the system's use for localization. Fingerprinting can be considered as an estimator which employs the RSS(received signal strength) measurements to calculate the most likely position of the user.

The localization method based on the RSS is mainly depending on large number of RSS observation data and consisting of off-line training and on-line positioning

The task of off-line training is using the machine $M$, to find the wireless signal vector $X$ and the location of the $Y$ mapping between $\mathrm{Y}=\mathrm{f}(\mathrm{X})$. Online stage by using $\mathrm{Y}=\mathrm{f}(\mathrm{x})$ for location estimation.as shown in figure 1:

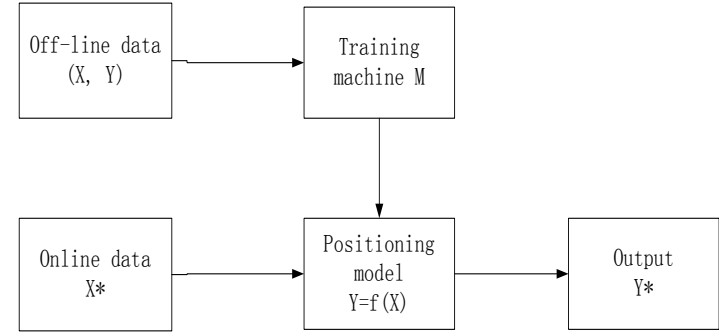

FIGURE I. LOCATION MODEL WITH FINGERPRINTING

Positioning based on RSS can be divided into two aspects: based on signal propagation model and based on the location of the fingerprint. The requirements of the first model for indoor propagation loss model is relatively high, so this paper apply the second model. Although RSS fingerprint positioning technology has been relatively mature but accurate indoor positioning is still a challenging research topic. In the actual environment, multipath propagation, non line of sight propagation, other electronic equipment signal and human interference, which makes the value of RSS in the receiving terminal has a certain randomness and instability, lead to the same place received Access Point(AP) signal intensity will change remarkably, so that the applicability of prediction model trained is greatly reduced.

To solve the problems above, this paper extracts the main components in the sample by PCA(Principal Component Analysis), to overcome the uncertainty influence brought by the change of environment, online phase using $\mathrm{K}$ nearest neighbour algorithm to locate.

\section{PCA MODEL FOR POSITIONING}

There are $\mathrm{n}$ wireless transmitting node (Access Point)and default $\mathrm{N}$ sampling points in location area, each sampling point position $\mathrm{l}_{\mathrm{i}}\left(\mathrm{x}_{\mathrm{i}}, \mathrm{y}_{\mathrm{i}}\right)$, constitute a position vector space $\mathrm{L}=\left(\mathrm{l}_{1}\right.$ $\left.\mathrm{l}_{2} \ldots \mathrm{l}_{\mathrm{i}} \ldots \mathrm{l}_{\mathrm{N}}\right)$ acquire each sampling point signal strength from $\mathrm{n}$ AP, form $\mathrm{a} n$ weft fingerprint vectors $\mathrm{F}_{\mathrm{i}}=$ $\left(\mathrm{rss}_{1}, \mathrm{rss}_{2} \ldots \mathrm{rss}_{\mathrm{n}}\right) \mathrm{i} \in(1, \mathrm{~N})$, which $\left(\mathrm{rss}_{\mathrm{i}}=\overline{\mathrm{rss}_{1, \mathrm{p}}}\right.$, as the average RSS multiple sampling, $r s s_{i}$ is from the i AP RSS value, constitute an ordered vector). The fingerprint information storage $\mathrm{N}$ collection points in the relevant database, these samples constitute aN $\times \mathrm{n}$ matrix $\mathrm{R}$. 


$$
\mathrm{R}=\left(\begin{array}{ccccc}
\mathrm{rss}_{11} & \mathrm{rss}_{12} & \ldots & \ldots & \operatorname{rss}_{1 \mathrm{n}} \\
\operatorname{rss}_{21} & \operatorname{rss}_{22} & \ldots & \ldots & \operatorname{rss}_{2 \mathrm{n}} \\
\ldots & \ldots & \ldots & \ldots & \ldots \\
\operatorname{rss}_{\mathrm{j} 1} & \ldots & \mathrm{rss}_{\mathrm{ji}} & \ldots & \operatorname{rss}_{2 \mathrm{n}} \\
\ldots & \ldots & \ldots & \ldots & \ldots \\
\mathrm{rss}_{\mathrm{N} 1} & \mathrm{rss}_{\mathrm{N} 2} & \ldots & \ldots & \operatorname{rss}_{\mathrm{N} 2}
\end{array}\right), \mathrm{R}=
$$

PCA process is as follows:

Step1. Calculate the average fingerprint sample $U$, $U$ isa n-column vector

$$
\mathrm{U}=\frac{1}{\mathrm{~N}} \sum_{\mathrm{i}=1}^{\mathrm{N}} \mathrm{F}_{\mathrm{i}}=\left(\mathrm{u}_{1}, \mathrm{u}_{2} \ldots \mathrm{u}_{\mathrm{n}}\right)
$$

Step2. Calculate the difference of fingerprint sample $d_{i}$, $\mathrm{d}_{\mathrm{i}}$ is a n-column vector

$$
\mathrm{d}_{\mathrm{i}}=\mathrm{F}_{\mathrm{i}}-\mathrm{U}, \quad \mathrm{i} \in(1, \mathrm{~N})
$$

Step3. Calculate he covariance matrix $\mathrm{C}$, which $\mathrm{A}=$ $\left(d_{1}, d_{2} \ldots d_{N}\right)$ forn $\times N$

$$
\mathrm{C}=\frac{1}{\mathrm{~N}} \mathrm{AA}^{\mathrm{T}} \mathrm{n} \times \mathrm{n}
$$

Step4. Calculate $C$ eigenvalues $\lambda_{\mathrm{i}}$ and the unit orthogonal eigenvectors $\mu_{\mathrm{i}}$, according to the eigenvalues of the contribution rate $\alpha=\sum_{\mathrm{i}=1}^{\mathrm{p}} \lambda_{\mathrm{i}} / \sum_{\mathrm{i}=1}^{\mathrm{n}} \lambda_{\mathrm{i}}$ take $95 \%$,calculate $\mathrm{C}$ the $\mathrm{P}$ largest eigenvalues and the corresponding orthogonal eigenvector .Structural features of fingerprint space $W=\left(\mu_{1}\right.$, $\left.\mu_{2} \ldots \mu_{\mathrm{p}}\right) \mathrm{n} \times \mathrm{p}(\mathrm{n}<\mathrm{p})$.

Step 5. Map R to C, get the mapping fingerprint spaceR'

$$
\mathrm{R}^{\prime}=\left(\mathrm{W}^{\mathrm{T}} \mathrm{A}\right)=\left(\mathrm{W}^{\mathrm{T}} \mathrm{d}_{1}, \mathrm{~W}^{\mathrm{T}} \mathrm{d}_{2} \ldots \mathrm{W}^{\mathrm{T}} \mathrm{d}_{\mathrm{N}}\right) \mathrm{N} \times \mathrm{p}
$$

So after PCA algorithm $N \times$ norder fingerprint sample space $\mathrm{R}$ inton $\times$ porder mapping fingerprint sample space $\mathrm{R}^{\prime}=$ $\left(\mathrm{F}_{1}^{\prime}, \mathrm{F}_{2}^{\prime} \ldots \mathrm{F}_{\mathrm{N}}^{\prime}\right)^{\mathrm{T}}$, sample dimension fromn down to $\mathrm{p}$, extract the main component fingerprint of the sample space, can overcome the impact of uncertain environmental factors.

\section{The Indoor Positioning ALgorithm BASEd ON WLAN}

The algorithm proposed in this paper, extract main components of samples by using PCA, can effectively eliminate the influence of environment on RSSI. The algorithm is mainly divided into two phase:

\section{off-line phase}

Collect $\mathrm{N}$ sample point positioning regional signal intensity from n AP, and each sampling point of gathering many times. Take from every AP average RSSI as the location fingerprint information, all $\mathrm{N}$ sampling location fingerprint point into fingerprint database, use PCA (principal component analysis) extract the $\mathrm{N}$ fingerprint samples, the n-dimension sample down to $\mathrm{p}$ dimension, so we get mapping fingerprint sample space $\mathrm{R}^{\prime}=\left(\mathrm{F}_{1}^{\prime}, \mathrm{F}_{2}^{\prime} \ldots \mathrm{F}_{\mathrm{N}}^{\prime}\right)^{\mathrm{T}}$.

\section{Online positioning stage:}

The fingerprint samples Sare on-linecollect fingerprint samples and the average samples $U$ difference map to fingerprint pace,get mapping fingerprint vectors $\mathrm{S}^{\prime}=$ $\mathrm{W}^{\mathrm{T}}(\mathrm{S}-\mathrm{U})$ is a $\mathrm{m}$ column vectors, estimates the location by KNN. In the database, $\mathrm{F}_{\mathrm{i}}$ and $\mathrm{F}_{\mathrm{i}}^{\prime}$ are the location $\mathrm{l}_{\mathrm{i}}\left(\mathrm{x}_{\mathrm{i}}, \mathrm{y}_{\mathrm{i}}\right)$ fingerprint information and the mapping fingerprint information. CalculateF $F_{\mathrm{i}}^{\prime}$ andS'Euclidean distance $\mathrm{D}_{\mathrm{i}}$.

$$
D_{i}\left(S^{\prime}, F_{i}^{\prime}\right)=\sqrt{\sum_{j=1}^{p}\left(s_{j}^{\prime}-r s s_{j}^{\prime}\right)^{2}}
$$

According the size of the $\mathrm{D}_{\mathrm{i}}$, found the $\mathrm{K}$ minimal $\mathrm{D}_{\mathrm{i}}$ and its corresponding location fingerprint and the location $\mathrm{l}_{\mathrm{i}}$,then:

$$
\text { position }=\frac{\sum_{i=1}^{K} \beta_{i} \cdot l_{i}}{\sum_{i=1}^{K} \beta_{i}} \beta_{i}=\frac{1}{D_{i}+d_{0}}
$$

\section{The Simulation Results}

This paper carries out the following simulation, virtual simulation in a $40 * 40 \mathrm{~m}$ room, between the sampling points spaced $1 \mathrm{~m}$, total of 1521 sample points, without considering the effect of AP location on RSS, compared KNN algorithm with the algorithm proposed in this paper. Simulation is carried out for different numbers of AP in same environmental, get the result shown in Figure 2.

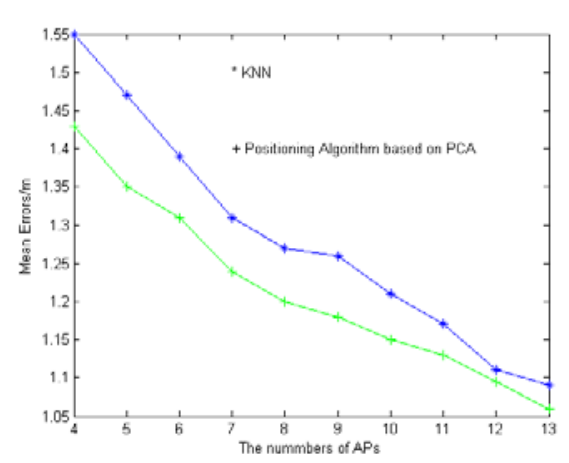

FIGURE II. SIMULATION BETWEEN KNN AND ALGORITHM BASED ON PCA

We can see that the average error was less than that of KNN algorithm, so this algorithm of anti-jamming performance is better than the KNN algorithm.

\section{CONCLUSION}

This paper presents the extracting ideal samples by PCA, which can reduce the environmental factors on the location results, then use KNN algorithm to estimate position. Through the simulation this algorithm is better than the existing KNN algorithm in anti-interference capability and accuracy.

\section{REFERENCE}

[1] Zhihong Qian, Yijun Wang. IoT technology and Application[J], Acta Electronica Sinica, 40(5)1023-1029.2012.

[2] V. Moghtadaiee, S. Lim, A.G. Dempster, System-level considerations for signal-of-opportunity positioning, in: Proc. of Int. Symp.GPS/GNSS, Taipei, Taiwan, 2070, pp. 302-308.

[3] B. Li, Y. Wang, H.K. Lee, A. Dempster, C. Rizos, Method for yielding adatabase of location fingerprints in WLAN, IEEE Proc. Commun. 152(5)580-586. 2005.

[4] P. Bahl, V. Padmanabhan, RADAR: an in-building RF-based userlocation and tracking system,in: Proc.IEEE Nineteenth Annual JointConference of the IEEE Computer and Communications SocietiesINFOCOM, 2, 775-784, 2000.

[5] N. Patwari, A. Hero, M. Perkins, N. Correal, R. 0'Dea, Relative locationestimation in wireless sensor networks, IEEE Trans. Signal Process.51(8)2137-2148. 